\title{
Entrevista com Carlos Hasenbalg
}

Por Antonio Sérgio Alfredo Guimarães

Carlos, vamos dar início à nossa entrevista via email? M inha primeira pergunta tem a ver com a relação causal entre discriminação racial e desigualdades sociais no Brasil, ou entre racismo e desigualdades raciais. Alguns intelectuais brasileiros ultimamente vêm tentando refutar esse elo causal. N ão sem razão, você tem sido lembrado como o primeiro autor nas nossas ciências sociais a estabelecer o elo entre discriminação e desigualdades raciais (no seu livro de 1979, D iscriminação e desigual dades raciais no Brasil). H oje, vocêcontinua a defender a tese de que as desigualdades sociais no Brasil decorrem, em grande medida, de discriminações raciais sistemáticas ou difusas com as quais os negros se deparam em diversas instâncias da vida social? Q ual o estatuto teórico da relação entre discriminação racial e desigual dades sociais?

Em D iscriminação e desigualdades raciais no B rasil, e em trabal hos poste riores em parceria com $\mathrm{N}$ elson do Valle Silva, procuramos desvendar os mecanismos e os processos geradores das desigual dades raciais no país. $\mathrm{N}$ ão nos ocupamos da questão de quanto o racismo e a discriminação racial contribuem para as desigualdades sociais em geral no Brasil.

Em D iscriminação..., fiz uma análise em parte histórica da geração das desigualdades raciais. U ma das causas importantes das disparidades entre os grupos de cor está na sua desigual distribuição geográfica, com os nãobrancos (das cores preta e parda) concentrados nas regiões menos desenvol- 
vidas, N ortee N ordeste, e os brancos concentrados nas regiões mais desenvolvidas, no Sul e Sudeste. Essa polarização geográfica foi historicamente condicionada pela dinâmica do sistema escravista no país e, desde a etapa final desse regime, pelas políticas de incentivo e subsídio à imigração européia no Sudestee Sul do Brasil. Tal polarização persisteatéhoje, como pode ser comprovado facilmente com os dados do IBGE, e setraduz em diferenças na apropriação de oportunidades sociais em áreas como educação, emprego, rendimentos etc.

Além disso, naquele livro de 1979, atribuía as desigualdades entre os grupos de cor ou raciais à discriminação racial e ao racismo. Cabe aclarar que, nesse livro e nos trabal hos posteriores com o $\mathrm{N}$ elson, a discriminação não éobservada diretamente. Ela éinferida a partir da análise da disparidade deresultados sociais dos grupos de cor, controlada pelas variáveis relevantes.

Um exemplo para ilustrar é o da desigualdade de rendimentos individuais dos grupos decor. 0 rendimento dosnão-brancosé aproximadamente a metade do dos brancos. É claro que toda essa diferença não é devida à discriminação. Parte dela obedece à diferente dotação de recursos dos dois grupos (educação, experiência no mercado de trabalho etc.). A parte da diferença de renda atribuída à discriminação é obtida por meio de um contrafactual. A plica-se a equação de renda dos brancos aos não-brancos e 0 valor obtido é comparado ao valor observado. A diferença entre esses valores é a atribuída à discriminação. U samos outros procedimentos nos trabaIhos sobre diferenças na realização educacional e sobre a mobilidade social dos grupos de cor. As diferenças de desempenhos de brancos enão-brancos são sempre observadas usando as variáveis de controle pertinentes, ou seja, a igualdade de outras condições, tais como origem social, renda familiar e nível educacional. Esses controles permitem tirar conclusões sobre as diferenças na apropriação de oportunidades sociais pelos grupos de cor ou raciais. Em todos os temas analisados durante mais de vinte anos, os nãobrancos acabam em desvantagem.

Como já disse, nesses trabalhos, baseados principalmente nos dados do IBG E, a discriminação racial não é observada diretamente. No entanto, nada impede que sejam feitos estudos qualitativos sobre padrões e situações de discriminação racial, baseados em notícias de jornais, denúncias em delegacias de polícia, organismos de DDH H e até mesmo em processos judiciais. Você, Antonio Sérgio, já publicou al go nessa direção e eu dei uma pequena contribuição sobre notícias na imprensa no apêndice de D iscriminação... 
Além do fator geográfico e das práticas discriminatórias, uma cultura racista está permeada de estereótipos e representações negativas de grupos minoritários (negros, mestiços, nordestinos, bolivianos etc.). Esses estereótipos culturais tendem a se autoconfirmar e acabam limitando as aspirações e as motivações, neste caso, das pessoas não-brancas. Em D iscriminação..., apontava que práticas discriminatórias e estereótipos se reforçam mutuamente e levam a que muitos negros e mestiços regulem suas aspirações de acordo com o queé culturalmente imposto como o "lugar apropriado" para os não-brancos. C aberia agregar que mudanças ideológicas globais, a ampliação do debate público sobre a questão racial, a atuação de movimentos sociais eorganismos de D D H H ea existência de convenções internacionais e legislação nacional contra o racismo levam a pensar que hoje os efeitos de bloqueio dessas representações sejam menores do que foram, digamos, no início ou em meados do século XX.

A pesquisa sociológica e demográfica sobre desigual dades raciais no Brasil não é nova nem escassa. D eixando de lado os estudos pioneiros do chamado "Projeto U nesco", a tradição de pesquisa desenvolvida nosúltimos 25 ou 30 anos dá forte sustentação à idéia de que os brasileiros não-brancos estão expostos a desvantagens cumulativas ao longo das fases do ciclo de vida individual, e que essas desvantagens são transmitidas de uma geração a outra. Em outros trabal hos resenhei boa partedesses estudos eaqui melimito a apontar os principais resultados.

Estudos demográficos demonstraram as disparidades raciais quanto às probabilidades de superar o primeiro ano de vida e à esperança de vida ao nascer. As pesquisas sobre educação indicam que crianças não-brancas completam menos anos de estudo do que as brancas, mesmo quando se consideram crianças de mesma origem social ou renda familiar per capita. As disparidades no acesso, permanência e finalização dos ensinos médio e superior são ainda mais acentuadas. A desigualdade educacional entre brancosenão-brancos irá se refletir posteriormenteem padrões diferenciados de inserção desses grupos de cor na estrutura ocupacional.

0 tema da participação dos grupos raciais no mercado de trabalho éum dos que está mais bem estudado. Resumindo esimplificando, esses estudos indicam que pretos e pardos estão expostos a diversas práticas discriminatórias no mercado de trabalho. Além de ingressar nele com uma dotação menor de educação formal que a dos brancos, os não-brancos estão expostos à discriminação ocupacional, pela qual a avaliação de atributos não produtivos, como a cor das pessoas, resulta na exclusão ou no acesso limitado a 
posições valorizadas no mercado de trabalho. Soma-se a isso a discriminação salarial, evidenciada nas menores taxas de retorno à educação e à experiência obtidas por não-brancos, ea diferença na taxa de retornos aumenta nosníveis educacionais mais el evados. Esses padrões diferenciados de participação dos grupos de cor no mercado de trabalho se traduzem em uma valorização altamente desigual do trabal ho desses grupos: a renda média do trabal ho de pretos e pardos é pouco menos da metade da dos brancos.

Por último, as pesquisas sobremobilidade social e raça, levando em conta 0 conjunto de processos sociais acima referidos, enfocam o papel da filiação racial na transmissão intergeracional das desigualdades sociais. Os resultados mais relevantes apontam não só para as menores taxas de mobilidade ascendente para os estratos médios e al tos experimentadas pel os nãobrancos, como também para as maiores dificuldades encontradas pelas famílias não-brancas de classe média para transmitir aos filhos as posições sociais conquistadas.

Diante de toda essa evidência acumulada na pesquisa sociológica e demográfica dos últimos tempos, o ônus da prova está com aqueles que tentam desfazer o elo causal entre racismo, discriminação e desigualdades raciais. Se as desigualdades raciais no Brasil não são produto de racismo e discriminação, qual é a teoria ou interpretação alternativa para dar conta das desigual dades constatadas?

Por último, quanto ao estatuto teórico da relação entre discriminação racial e desigualdades sociais, queria apenas referir a orientação adotada nos trabalhos anteriores sobre o tema com $\mathrm{N}$ el son do Valle. $\mathrm{N}$ esses trabalhostomamos como ponto de partida uma revisão crítica da literatura sobre relações raciais no Brasil, constatando que o papel de "raça" ou cor no processo estratificatório ou ésimplesmente desconsiderado, no caso das análises que vêem o preconceito ea discriminação como um mero epifenômeno das relações de classe, ou é então minimizado, quando a verificação da existência conspícua de comportamentos e atitudes discriminatórias é explicada como constituindo um "arcaísmo" evanescente do passado escravista. N esses trabalhos foi enfatizada a funcionalidade da discriminação racial como instrumento de desqualificação de grupos sociais no processo de competição por benefícios simbólicos e materiais, resultando em vantagens para o grupo branco em relação aos grupos não-brancos (preto e pardo). Tentamos mostrar que preconceito e discriminação raciais estão intimamente associados à competição por posições na estrutura social, refletindo-se em diferenças entre os grupos de cor na apropriação de posições na hierarquia social. N ova- 
mente, esse enfoque diz respeito às desigual dades entregrupossociais, o que C harles Tilly chamou de desigual dades categóricas, e não às desigualdades sociais em geral.

C abe agregar que quando estudamos essas desigual dades, opondo brancos/não-brancos (pretosepardos), nos referimos estritamentea processos de estratificação socioeconômica. Q uando examinamos outras dimensões da vida social envolvendo a sociabilidade dos indivíduos (por exemplo, o casamento e a amizade), esse padrão não se verifica, os pardos se diferenciando dospretoseseaproximando mais dosbrancos. Poder-se-ia dizer queháuma disjunção aparente entre o processo de estratificação, que diz respeito ao funcionamento das principais instituições (escola emercado detrabal ho), e a vida social dos indivíduos, caracterizada por barreiras mais fluidas eambíguas. Essa disjunção tende a corresponder à distinção feita por Sansone (1993) entreas "áreas duras" eas "áreas moles" das relações raciais no Brasil.

O u seja, o racismo ea di scriminação racial, tendo em conta evidênciasempíricas, sejam elas recol hidas de dados quantitati vos, sejam de observações partici pantes ou documentos, ainda éa explicação mais sólida para as disparidades de renda entre brancos e negros no Brasil. Como você, em seus estudos de desi gualdades raciais, se confronta com a quetão da fluidez e da ambigüidade das identidades raciais no Brasil? Explico-me: nos anos de 1950, Thales de Azevedo notou uma grande superposição entre "brancos" e "ricos", por um lado, e "pretos" e "pobres", por outro. Tomou mesmo esses termos classificatórios dos sistemas racial e de classe como sinonímias nativas. Dado que a cor regi strada pelo IBGE é autodeclarada e dada a fluidez do nosso sistema classificatório racial e a sua associação com o sistema de classes, poder-se ia argumentar queno grupo "branco" estariam muitas pessoas de ascendência africana, digamos "pardos ricos", quese dedaram "brancos". I sso poderia inflar a riqueza dos "brancos" eempobrecer os "negros". Esse argumento é verdadei ro? N o que ele afeta os seus resultados?

Continuo achando que racismo e discriminação racial, no passado e no presente, constituem a explicação mais sólida para as desigual dades raciais. A disparidade de renda entre brancos e não-brancos é talvez 0 aspecto mais gritante das desigualdades. $M$ as, insisto, pretos e pardos estão expostos a desvantagens em todas as etapas do ciclo de vida. O s demógrafos constataram que as mulheres pretas e pardas têm taxas de mortalidade intra-uterina mais el evada do que as mulheres brancas, que as taxas de mortalidadeinfantil (T M I) e de mortalidade demenores de cinco anos (T M M 5) são substan- 
cialmente mais elevadas entre os não-brancos, e que pretos e pardos vivem em média cinco ou seis anos menos que os brancos. As trajetórias escolares de crianças e jovens não-brancos são mais acidentadas e curtas do que as de seus pares brancos. A desigualdade de renda entre os grupos de cor reflete padrões diferenciados de inserção no mercado de trabal ho e práticas discriminatóriasnesse mercado, mas são também devidas às desvantagen sacumuladas nas etapas formativas, anteriores ao ingresso no mercado de trabal ho.

A segunda parte da pergunta remete a duas questões relacionadas. A primeira refere-se à passagem do sistema de categorias de identidade racial ou de cor usado pelos brasileiros - caracterizado pela fluidez e ambigüidade - para o sistema classificatório de cor censitário do IBGE, que pede aos entrevistados para identificar-se em um grupo fechado de categorias de cor (branca, parda, preta e amarela, com o acréscimo de indígenas a partir do censo de 1991).

A segunda questão é se a autoclassificação de cor na pergunta censitária está contaminada pela situação socioeconômica do respondente, havendo um possível efeito de embranquecimento. Essas questões foram discutidas de maneira detal hada em dois trabal hos de $\mathrm{N}$ elson do Valle Silva e vou me remeter a al guns de seus argumentos para responder.

0 que está em jogo no primeiro ponto é saber se a pergunta fechada do censo e das PN AD sétida como uma referência à característica demográfica cor da pele ou está destinada a pesquisar identidades coletivas por meio das preferências verbais dos entrevistados quanto à sua autodenominação de cor. A primeira hipótese é enfaticamente defendida por $\mathrm{N}$ elson, e eu concordo completamentecom ele (cf. Silva, 1999a). Em boamedida, essa disjuntiva está relacionada à categoria "morena".

A PN AD de 1976 fazia primeiro uma pergunta aberta, permitindo aos entrevistados declarar a sua cor espontaneamente, e logo fazia a pergunta fechada, pedindo aos respondentes para escolher entre as cores branca, preta, parda e amarela. $\mathrm{N}$ as respostas à pergunta aberta, uma percentagem elevada (35\%) de entrevistados se declarou de cor morena clara e morena. Resultados semel hantes foram obtidos na pesquisa $D$ atafolha de 1995 sobre a questão racial: na auto-identificação de cor, $42 \%$ dos entrevistados se declarou de cor morena clara e morena.

Essa elevada preferência pela categoria moreno levou a que fosse sugerida sua inclusão no quesito cor do censo e das PN AD s. 0 problema reside em que, quando se cruzam as respostas à pergunta aberta com a pergunta fechada, os autodeclarados morenos se distribuem em todo o leque das cate- 
gorias de cor fechadas. N o caso da PN AD 1976, os que se declararam brancos, pardos e pretos na pergunta aberta se reclassificam de maneira consistente no quesito censitário fechado. Já os que optaram pela cor morena se reclassificaram da seguinte forma no quesito fechado: $22 \%$ brancos, $67 \%$ pardos e 8,5\% pretos. Como observa Silva (1999a, p. 87), referindo-se a autores que já tinham estudado esse tema: "D efato, o termo moreno parece aplicável no Brasil a qual quer tipo físico, com exceção das pessoas louras, ruivas ou pretas de cabelos encaracolados".

$\mathrm{Na}$ categoria moreno pode estar a clave (ou chave) para desvendar 0 sistema de identidades raciais e outros aspectos importantes das relações raciais no Brasil, mas ela étotal mente inapropriada para se registrar a característica demográfica cor da pele.

A segunda questão, sobre o efeito de embranquecimento e a contaminação das respostas ao quesito cor por características socioeconômicas dos respondentes, também foi tratada com rigor estatístico por $\mathrm{N}$ elson do Valle Silva em "U ma nota sobre raça social no Brasil" (1999b), com base nos dados do survey realizado conjuntamente pelo Idesp e o Iuperj, "As eleições de 1986 em São Paulo". Para ser breve, limito-me a citar as conclusões desse autor.

Em outras palavras, as correlações obtidas entre cor e situação socioeconômica podem, de fato, estar inflacionadas pela utilização da autoclassificação de cor, relativamente ao que se obteria caso dispuséssemos de uma medida mais objetiva, mais fenotípica das características raciais dos indivíduos. A razão fundamental desse viés parece residir na natureza social do cálculo da identidade racial brasileira. As evidências aqui coletadas apóiam a idéia de que, no Brasil, não só o dinheiro embranquece como, inversamente, a pobreza também escurece (cf. Silva, 1999b, pp. 123-124).

G ostaria de lembrar aqui que esse efeito de embranquecimento já tinha sido notado por 0 racy N ogueira na década de 1950 em seu célebre relatório sobre Itapetininga e no não menos brilhante artigo sobre preconceito racial de origem e preconceito racial de marca. $N$ otava N ogueira nesses trabal hosque, enquanto nos Estados U nidos o sucesso socioeconômico dos negros permanecia dentro da comunidade negra, no Brasil parte do sucesso das pessoas de cor era contabilizado no grupo branco, pela incorporação de mestiços claros bem-sucedidos nesse grupo.

Finalmente, dada a ausência de uma mensuração não contaminada da cor das pessoas, é impossível determinar o quanto a correlação entre a cor declarada nas pesqui sas do IBGE e a situação socioeconômica se vêaumen- 
tada. M as me inclino a pensar que, se essa mensuração existisse, a correlação continuaria muito elevada.

U ma última pergunta: vocêacha que o sistema de cotas quevem sendo adotado por mais de vinte universidades públicas brasile ras, assim como o ProU ni, tem condi ç̃es de reverter ou minorar o quadro das desi gualdades raciais no Brasil? Foi essa a razão que o levou a apoiar publicamente essa política?

Estranho seria se quem pesquisou e denunciou as desigualdades raciais no Brasil durante mais de vinte anos não apoiasse o sistema de cotas e programas como o ProUni.

A primeira razão de peso para ser favorável a essas políticas tem a ver com o papel crucial da educação no processo de mobilidade social. N o último trabalho com o $\mathrm{N}$ elson sobre esse tema, exploramos esse papel da educação nas diferenças raciais de mobilidade ocupacional no Brasil. Permitome citar por extenso as conclusões a que chegamos.

Como indicamos anteriormente, a literatura sociológica que trata das diferenças socioeconômicas por cor no B rasil aponta para a existência de um processo de cumulação de desvantagens. $N$ esse trabal ho constatamos, mais uma vez, a plausibilidade detal caracterização. Além disso, parece claro que no Brasil de hoje o núcleo das desvantagens que pretos e pardos parecem sofrer se localiza no processo de aquisição educacional. As diferenças nos retornos ocupacionais dos investimentos em educação são relativamente modestas quando comparadas com as diferenças na realização educacional, qualquer que seja o estrato social de origem. D iferenças que, como vimos, tendem a crescer conforme se eleva a situação socioeconômica de origem. Assim, a questão educacional parece estar se constituindo no nó górdio das desigualdades raciais no nosso país (cf. H asenbalg eSilva, 1999, p. 229).

$N$ a mesma direção aponta um trabalho econométrico recente de Sergei Soares, destinado a decompor as diferenças de renda entre grupos de cor e sexo. No que se refere aos diferenciais entre grupos de cor, a desigualdade educacional é o principal fator explicativo das disparidades de renda (cf. Soares, 2000).

As diferenças no acesso, desempenho e permanência dos grupos de cor no sistema educacional aumentam nos níveis de ensino mais elevados. A título de ilustração, cito um dado recente divulgado pelo IBGE sobre a distribuição dosgrupos de cor pelos diferentes níveis de ensino: “Em 2004, $47 \%$ dos estudantes de 18 a 24 anos de cor branca freqüentavam o ensino 
superior, uma proporção quase três vezes superior à encontrada para os estudantes de cor preta e parda (16,5\%)" (Síntese de Indicadores Sociais 2005 , p. 256). Isso significa que $82,5 \%$ dos estudantes não-brancos dessas idades estavam ainda cursando os níveis de ensino fundamental e médio, coisa que ocorria com somente $53 \%$ dos alunos brancos.

0 efeito esperado das políticas de cotas raciais nas universidadespúblicas e de vagas para alunos de famílias carentes nas universidades privadas, incluindo pretos e pardos, por meio do ProU ni, éo aumento da presença de não-brancos em posições sociais de destaque. Isso, por sua vez, deverá socavar os estereótipos negativosque, como já mencionei, delimitam os "lugares apropriados" para os não-brancos. Trata-se de acelerar significativamente a incorporação denão-brancosem papéisque propiciem modelos deidentificação (rolemodels).

$\mathrm{N}$ as discussões com $\mathrm{N}$ el son do Valle sobre esse tema, chegamostambém à conclusão de que a questão tempo é essencial: mesmo na ausência de mecanismos discriminatórios, a eliminação das desigualdades raciais levaria várias gerações, se deixada aos ritmos naturais. Por outro lado, dada a aparente existência de tais mecanismos, estamos diante de um custo social evitável: além da presença de questões fundamentais relativas à justiça social e à eqüidade, a existência de mecanismos discriminatórios representa um desperdício do que os economistas chamam de "capital humano", já que não estamos aproveitando todo o potencial de pessoas talentosas, cujo talento não pode ser expresso por causa das menores oportunidades e incentivos de que os não-brancos dispõem. 0 argumento passa então também pela maior eficiência de uma sociedade mais igualitária nas oportunidades, o que justificaria ações afirmativas para incentivar e propiciar 0 florescimento dos membros mais talentosos das minorias.

Esses são al guns dos principais motivos que me levam a tomar posição nesse tema.

Referências Bibliográficas

H Asen balG, C. (1979), D iscriminação e desigualdades raciais no Brasil. Rio de Janeiro, Graal (2 ed. 2005, Belo H orizonte/Rio de Janeiro, Editora U FM G/luperj/ U cam).

H asen balg, C . \& Silva, N . V. (1999), "Educação e diferenças raciais na mobilidade ocupacional". In: Hasen balg, C.; Silva, N. V. \& LIma, M . (orgs.), Cor e estratificação social. Rio de Janeiro, Contracapa. 
N ogueira, O racy. (1985), "Preconceito racial de marca e preconceito racial de origem: sugestão de um quadro de referência para a interpretação do material sobre relações raciais no Brasil". (org.), Tanto preto quanto branco: estudos de relações raciais، $1^{a}$ edição 1959. São Paulo, T. A. Q ueiroz.

. (1998), Preconceito de marca: as relações raciais em Itapetininga. $1^{a}$ edição 1955. São Paulo, Edusp.

SANSONE, L. (1993), "Pai preto, filho negro: trabalho, cor e diferenças de gerações". Estudos Afro-A siáticos, 25.

Silva, N . V. (1999a), "M orenidade: modos de usar". In: H asen balg, C.; Silva, N . V. \& LıMA, M. (orgs.), Cor e estratificação social. Rio de Janeiro, Contracapa, pp. 86-106.

. (1999b), "U ma nota sobre raça social no Brasil". In: H asen balg, C.; Silva, N. V. \& LıMA, M . (orgs.), Cor e estratificação social. Rio de Janeiro, Contracapa, pp. 107-125.

SoARes, S. S. D. (2000), "O perfil da discriminação no mercado de trabalho: homens negros, mulheres brancas e mulheres negras". I pea, Textos para D iscussão, ก. 769.

Antonio Sérgio Alfredo Guimarães é professor de sociologia na UniversidadedeSão Paulo. E-mail: asguima@usp. br. 